\title{
Economia solidária, uma alternativa à geração de trabalho e renda em território semiárido: dificuldades e perspectivas $^{1}$
}

\author{
Resumo
}

\author{
Kleber Ávila Ribeiro*
}

\begin{abstract}
Este trabalho tem por objetivo mostrar o perfil socioeconômico das associadas e os gargalos que dificultam a sobrevivência dos empreendimentos de economia solidária, em particular, o da Associação de Mulheres Rendeiras no município de Petrolina, Pernambuco, impedindo-os, muitas vezes, de atuar como instrumento de geração de trabalho e renda em um território com poucas oportunidades econômicas. A metodologia utilizada para elaboração deste trabalho consistiu de uma pesquisa documental e de coleta de dados secundários realizada mediante aplicação de questionários estruturados em um universo amostral de 27 associados, realizada de 24 a 31 de outubro de 2014. Concluiu-se que a dificuldade de acesso às linhas de crédito tradicional convencional, a falta do conhecimento de instrumentos de gestão e falta de atuação em redes solidárias constituem-se nos principais entraves à sustentabilidade desse tipo de empreendimento solidário e autogestionário.
\end{abstract}

Palavras-chave: Associativismo. Economia solidária. Geração de trabalho e renda.

* Professor. Universidade do Estado da Bahia, Colegiado de Direito, Itaberaba, Bahia. E-mail: ribeirokleber68@gmail.com

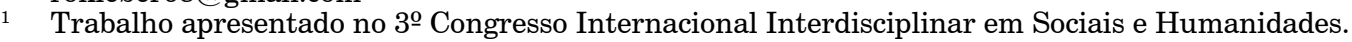

http://dx.doi.org/10.5335/rtee.v22i46.6753

Submissão: 10/03/2016. Aceite: 24/05/2016. 


\section{Introdução}

A partir da queda do regime feudal na Europa Ocidental no final do século XVII, que terminou culminando na primeira Revolução Industrial, surgiu um novo modelo de produção, modelo fundamentado na propriedade privada dos meios de produção:

São características desse período as ideias de Taylor e Ford no que tange ao modo de organização do trabalho. Tais ideias tiveram origem em suas experiências na fábrica metalúrgica e automotiva, respectivamente, que acabaram espraiando-se para uma série de atividades de trabalho, [...] desde a industrial, passando pela agrícola, financeira, comercial, governamental etc. (PINTO, 2007, p. 27).

Assim, nesse período, o continente europeu vivia um quadro caótico nos âmbitos econômico, político e social, cenário proporcionado pelos seguintes fatores: a) os comerciantes e os mercadores europeus eram considerados os principais manufaturadores e comerciantes do mundo, além disso, detinham em suas mãos a confiança e a reciprocidade dos governantes quanto à manutenção da economia em seus estados, pela existência de um mercado em expansão para seus produtos, em que a Índia, a África, a América do Norte e a América do Sul eram integradas ao esquema da expansão econômica europeia; b) pelo contínuo crescimento da população, que oferecia um mercado sempre crescente aos bens manufaturados, além de uma reserva adequada (e posteriormente excedente) de mão de obra. Essa agenda resultou diretamente na exclusão dos artesãos do mercado de trabalho pelos avanços científicos que propiciaram o desenvolvimento da economia de escala e na precarização das relações de trabalho. $\mathrm{Na}$ esteira desse pensamento, Singer e Souza afirmam que "O capitalismo pós-industrial tem sido marcado pela deterioração das relações de trabalho. Um contingente populacional cada vez maior está se submetendo a condições de trabalho aviltantes: longas jornadas, baixa remuneração, desproteção legal e instabilidade" (2000, p. 27).

Dessa forma, contrapondo-se ao modo de produção capitalista, com o intuito de combater as precárias condições de trabalho, surgem os primeiros movimentos sociais de cunho associativo visando à melhoria da qualidade de vida dos trabalhadores, marcando o aparecimento das primeiras uniões de ofício e as primeiras cooperativas. Em 1844, na cidade de Rochdale, Grã-Bretanha, foi fundada a primeira cooperativa de consumo, consolidando, a partir de então, o cooperativismo como forma de associativismo, disseminando-se a cultura de cunho associativo por todo o continente europeu expandindo-se pelo mundo inteiro, com a economia solidária 
atuando na produção, no consumo e na distribuição das riquezas geradas pelas atividades econômicas voltadas para a valorização do homem, e não somente do capital.

No Brasil, os movimentos ligados à economia solidária desempenham importante papel na sociedade, englobando aspectos sociais, econômicos, políticos, ambientais e culturais, visto que, além da visão econômica de geração de trabalho e renda, as experiências de economia solidária estão no espaço público onde se encontram inseridas e são projetadas, tendo como perspectiva a construção de um ambiente socialmente justo, solidário e sustentável, objetivando promover a inclusão social das pessoas em situação de vulnerabilidade social, em especial aquelas que estão excluídas do mercado formal de trabalho.

Alguns fatores são tidos como fundamentais para o crescimento da economia solidária no país, tais como a crescente exclusão dos trabalhadores do mercado, o desemprego urbano crescente e o êxodo rural, consequências da globalização e do sistema capitalista. A luta pela sobrevivência na conformação de um mercado informal cada vez mais presente e crescente, em que iniciativas de economia popular, normalmente de caráter individual ou familiar, surgem com muita força e se manifestam sob a forma de empreendimentos de cunho associativo e solidário, voltados também à reprodução da vida, aponta para alternativas estruturais de organização da economia, baseadas em valores como a ética, a equidade e a solidariedade, e não mais no lucro e no acúmulo indiscriminado de capital.

Desse modo, devido à crescente organização da economia solidária como movimento nas últimas décadas no Brasil, e perpassando a dimensão de iniciativas isoladas e fragmentadas quanto à sua inserção nas cadeias produtivas e nas articulações do seu entorno, é que surgiu a Secretaria Nacional de Economia Solidária. Criada durante o governo Lula (2003-2010), simultaneamente, foi criado o Fórum Brasileiro de Economia Solidária, representante desse movimento no país, tendo como objetivo garantir a articulação entre os três segmentos do movimento de economia solidária: empreendimentos solidários (segmento em questão neste artigo), entidades de assessoria, fomento e gestores públicos.

Existem empreendimentos econômicos solidários (EES) produtivos nas mais diversas áreas econômicas: associações, cooperativas em agropecuárias, agroindustriais, industriais, de transporte, de artesanato, de reciclagem de resíduos sólidos, de educação escolar, de hotelaria, etc., além de ecovilas e outras iniciativas.

Diante desse contexto, o presente trabalho busca mostrar quais os gargalos que dificultam a sobrevivência dos empreendimentos solidários, em particular, o da Associação de Mulheres Rendeiras no município de Petrolina, Pernambuco, e que impedem esses estabelecimentos de atuar como instrumento de geração de emprego e renda em um território onde existem poucas oportunidades econômicas de sobrevivência. 


\section{Conhecendo o território...}

O município de Petrolina (BRASIL, 2010) está localizado na área da região semiárida, na mesorregião geográfica do São Francisco Pernambucano (Figura 1), e faz parte da Região Administrativa Integrada de Desenvolvimento (Ride) do polo Petrolina, Pernambuco, e Juazeiro, Bahia. Tem área de $4.558,4 \mathrm{~km}^{2}$, uma população estimada em 319.893 habitantes, com densidade populacional de $64,44 \mathrm{hab} . / \mathrm{km}^{2}$. Petrolina, nos últimos dez anos, conseguiu melhorar seu Índice de Desenvolvimento Humano Municipal (IDHM) em 20,17\%, chegando ao índice atual de 0,697 , com um produto interno bruto de 2.971.554 (em mil reais).

Figura 1 - Mesorregiões do estado de Pernambuco

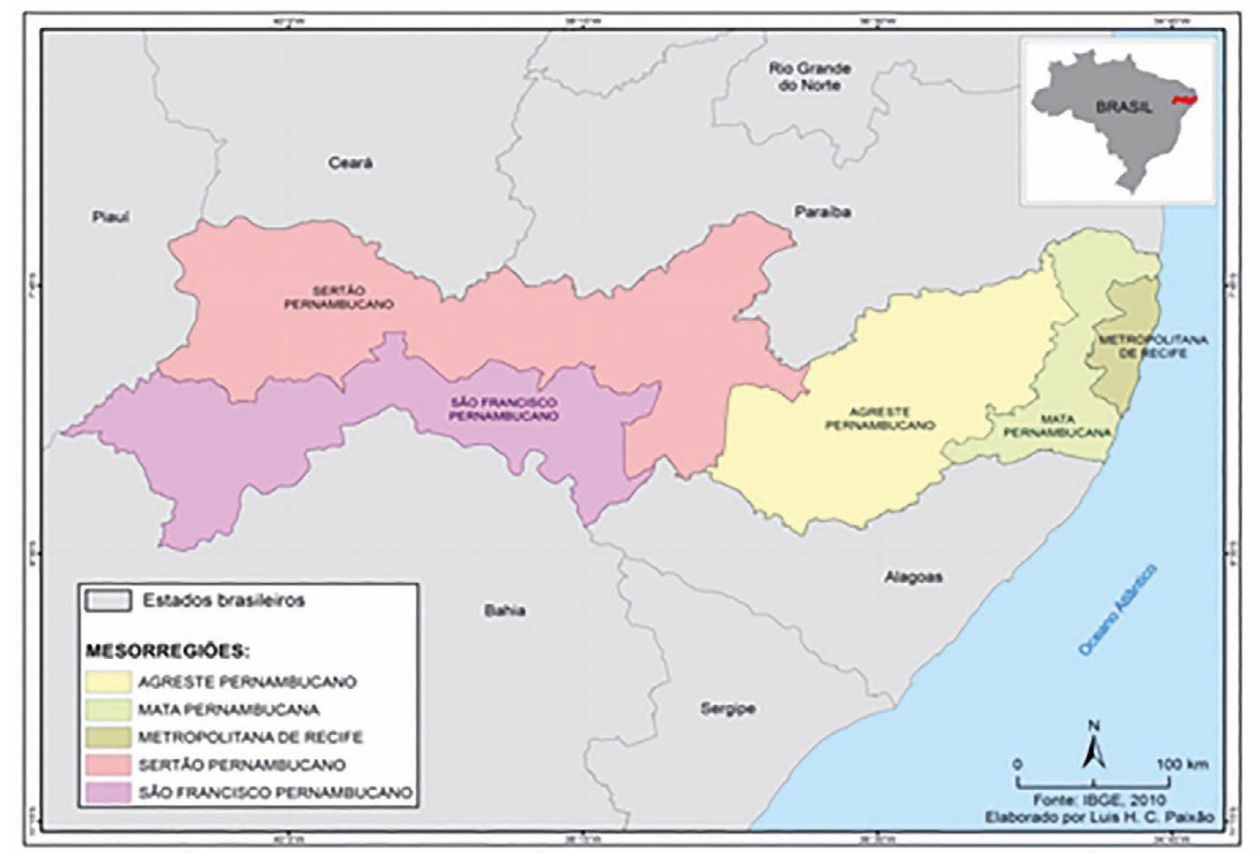

Fonte: IBGE (2010); elaborado por Paixão (2014).

Conforme observa-se na Tabela 1, a microrregião de Petrolina (Figura 2) é composta por oito municípios, Santa Maria da Boa Vista e Petrolina são considerados os mais importantes, possui uma densidade demográfica de 64,44 hab. $/ \mathrm{km}^{2} \mathrm{e}$ renda domiciliar de $\mathrm{R} \$ 584,31$, contra $\mathrm{R} \$ 402,34$ de renda domiciliar média dentro da microrregião. Destaca-se na atividade vitivinícola, em que representa $15 \%$ do 
mercado nacional da produção de vinhos. Segundo Arcoverde: "Além do vinho, a região contempla a maior produção de frutas do País, sendo responsável por $30 \%$ das exportações brasileiras do setor" (2009, p. 6). A região ainda inclui indústrias, comércio e agricultura em geral, com as mesmas características de toda a mesorregião.

Tabela 1 - Microrregião de Petrolina

\begin{tabular}{l|r|c|c|c|c}
\hline \multicolumn{1}{c|}{ Território } & Área $\left(\mathrm{km}^{2}\right)$ & População & Densidade $\left(\mathrm{km}^{2}\right)$ & Renda domiciliar & IDHM \\
\hline Afrânio & $1.490,6$ & 16.277 & 10,92 & 228,60 & 0,588 \\
Cabrobó & $1.657,9$ & 28.793 & 17,37 & 290,45 & 0,623 \\
Dormentes & $1.537,6$ & 15.476 & 10,07 & 255,97 & 0,589 \\
Lagoa Grande & $1.852,3$ & 22.379 & 12,08 & 292,90 & 0,597 \\
Orocó & 554,8 & 10.894 & 19,64 & 219,76 & 0,610 \\
Petrolina & $4.558,4$ & 319.893 & 70,18 & 584,31 & 0,697 \\
Sta. Ma da Boa Vista & $3.001,2$ & 44.053 & 14,68 & 264,56 & 0,590 \\
Terra Nova & 321,4 & 8.140 & 22,33 & 235,50 & 0,599 \\
\hline
\end{tabular}

Fonte: elaborada pelo autor com base em IBGE (2010).

Figura 2 - Município de Petrolina e microrregiões do estado de Pernambuco

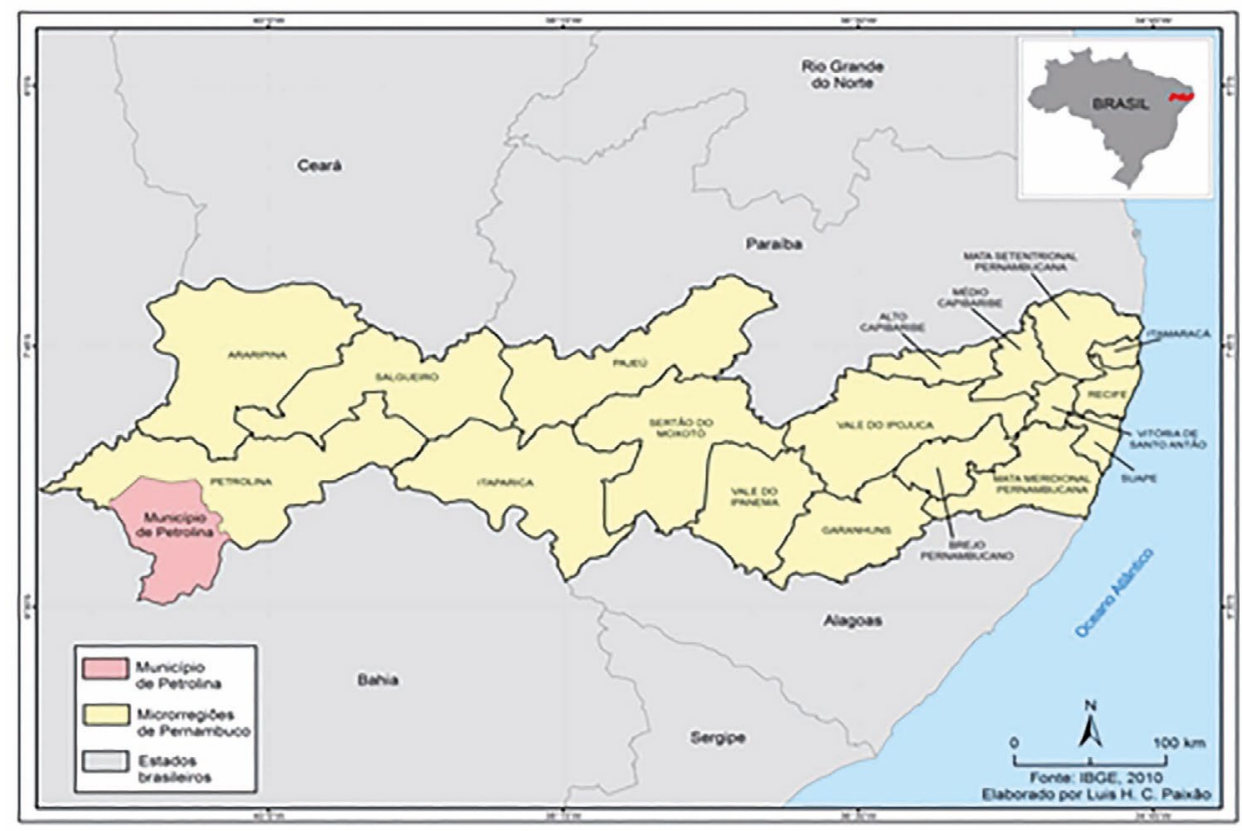

Fonte: IBGE (2010); elaborado por Paixão (2014). 


\section{Considerações gerais sobre os empreendimentos solidários}

A partir de década de 1980, o número de empreendimentos econômicos solidários cresce de forma significativa no Brasil. Atribui-se isso à trajetória do desenvolvimento do país, atrelado aos processos de industrialização e urbanização, que, por sua vez, foram interrompidos por uma série de crises, induzida, na maioria das vezes, por fatores exógenos, que levaram a um descontrole inflacionário, cujas consequências arrastaram-se por uma década e meia. Inúmeras tentativas malsucedidas de controle da inflação, com a implantação de planos econômicos ortodoxos, terminaram por contribuir para o agravamento da instabilidade econômica. De acordo com Singer e Souza:

[...] as tentativas de jugular a disparada dos valores monetários mediante planos de congelamento de preços, destinados a quebrar a inércia inflacionária, agravaram a instabilidade econômica e submeteram as classes trabalhadoras a intensas ondas de exclusão social e econômica sob a forma de desemprego em massa, favelização e precarização das relações de trabalho (2000, p. 129).

Sendo assim, o mercado formal de trabalho no Brasil, enfraquecido pelas crises institucionais internas, motivadas pelas crises no cenário internacional, que se sucederam ao longo da década de 1980, teve seu quadro agravado ainda mais no início dos anos 1990, com o advento da abertura comercial promovida pelo governo Collor (1990-1992). O processo de abertura provocou profundas mudanças estruturais no país, motivado pela convergência de fatores, com destaque: a) o fenômeno da globalização da economia, que levou ao acirramento dos mercados e ao aumento da concorrência; b) a reestruturação da cadeia produtiva nacional, com vistas a tornar competitiva a indústria nacional diante da concorrência estrangeira; c) a revolução tecnológica levou à extinção de inúmeros postos formais no mercado de trabalho, criando uma superpopulação de trabalhadores desnecessários ao processo de acumulação capitalista, contribuindo, ainda mais, para o agravamento da precarização de relações de trabalho.

Diante dessa conjuntura, aqueles trabalhadores excluídos do mercado formal de trabalho viram-se perante a necessidade de adotar diferentes estratégias de sobrevivência. É quando surge a economia solidária, cujas características são as iniciativas de produção, distribuição, comercialização, consumo e distribuição organizadas por grupos de trabalhadores que criam empreendimentos, que detêm a posse coletiva dos meios de produção, de cunho associativista e geridas pelos próprios 
trabalhadores, dando ao empreendimento uma característica autogestionária, cujos ganhos são repartidos entre os associados segundo critérios de justiça distributiva, conforme a quantidade de trabalho realizado por cada um. Segundo Lima:

[...] é o processo de transformação de trabalhadores que, até serem atingidos pelas crises, eram assalariados condicionados a cumprir tarefas e horários, em autogestores de seu próprio empreendimento, envolvidos na tomada de decisões de produção, comercialização e finanças, cujos efeitos - positivos ou negativos - são solidariamente partilhados por todos (2013, p. 48).

Os EES representam para a economia solidária as mais variadas maneiras de sua manifestação e são, ainda, considerados pelo Fórum Brasileiro de Economia Solidária (FBES) o público-alvo e a maioria da representação nas suas instâncias decisórias.

São considerados, dentre as mais diversas formas de organização da economia solidária (Tabela 2), os empreendimentos autogestionários, tais como as cooperativas, em seus diversos ramos de atividade, as associações populares e os grupos informais (de produção, de serviços, de consumo, de comercialização e de crédito solidário, nos âmbitos rural e urbano), empresas recuperadas de autogestão (antigas empresas capitalistas falidas recuperadas pelos trabalhadores), organizações de agricultores familiares, fundos solidários e rotativos de crédito (organizados sob diversas formas jurídicas e também informalmente), clubes e grupos de trocas solidárias (com ou sem o uso de moeda social ou moeda comunitária), ecovilas, redes e articulações de comercialização e de cadeias produtivas solidárias, instituições de comércio justo, agências de turismo solidário, entre outras formas de projetos. Em consonância com essas informações, Singer registra que:

[...] o fato dos empreendimentos solidários estarem se organizando e compondo redes de ajuda mútua e representação política aponta um dado interessante: a mobilização mais ampla em torno dessa proposta econômica e social está abrangendo as experiências populares de pequeno porte, de caráter informal e baixa rentabilidade. Ou seja, o lado bastante precário da economia brasileira, marcado pelo improviso e pela criatividade popular (1999, p. 40).

Desse modo, uma característica importante nos empreendimentos solidários é a maneira como os princípios e valores expressos na Carta de Princípios da Economia Solidária são restritamente tomados como base. Entre eles, destacam-se o exercício da autogestão na sua organização interna e o fato de serem suprafamiliares com caráter de atividade econômica, por ter seu capital constituído por cotas distribuídas por igual entre todos os membros que, dessa forma, são sócios do empreendimento. O princípio geral da autogestão é que todos os que trabalham são donos do empreendimento e todos os que são donos trabalham no empreendimento. Conforme Singer:

Teoria e Evidência Econômica - Ano 22, n. 46, p. 54-72, jan./jun. 2016 
[...] a Economia Solidária [...] lança os alicerces de novas formas de organização da produção, à base de uma lógica oposta àquela que rege o mercado capitalista, [...] permitirá [...] dar a muitos, que esperam em vão um novo emprego, a oportunidade de se reintegrar à produção por conta própria individual ou coletiva (1999, p. 138).

Segundo informações do Sistema Nacional de Informações em Economia Solidária (SIES) (2013), em todo o território nacional existem em torno de 33.518 EES identificados, dos quais, 11.663 são de novos empreendimentos mapeados nos últimos três anos, demonstrando como a economia solidária apresenta um dinamismo social e econômico independente do contexto de crise do desemprego e do fenômeno do dessalariamento que caracterizou o período das últimas décadas.

Tabela 2 - Quanto às formas de organização dos EES no Brasil (2010-2012)

\begin{tabular}{l|c|c}
\hline \multicolumn{1}{c|}{ Forma de organização } & Quantidade & Percentual (\%) \\
\hline Grupo informal & 6.018 & 30,5 \\
Associação & 11.823 & 60,0 \\
Cooperativa & 1.740 & 8,8 \\
Sociedade mercantil & 127 & 0,6 \\
Total & 19.708 & 100 \\
\hline
\end{tabular}

Fonte: elaborada pelo autor com base em dados do Sies (2013).

Como já visto, os EES apresentam-se sob diversas formas de organização e encontram-se distribuídos geograficamente ao longo do território nacional, como se pode observar na Tabela 3. Nas regiões Sul e Sudeste, existe um predomínio maior da participação de grupos informais, cuja participação supera a média nacional (44\% e 48,5\%, respectivamente). Sob a forma de cooperativas, o destaque recai sobre a região Sul, com uma participação de $18,4 \%$, contra uma média nacional de $8,8 \%$, e a região Nordeste destaca-se pela forma associativa, em que $74,2 \%$ dos EES estão organizados sob a forma de associação.

Tabela 3 - Quanto às formas de organização por região do Brasil (2010-2012)

\begin{tabular}{l|r|c|c|c|r|r|r|r|r|r|r|c}
\hline Forma de organização & NO & \multicolumn{1}{c|}{ \% } & NE & \% & SE & \% & SUL & $\%$ & CO * & \% & Brasil & $\%$ \\
\hline Grupo informal & 802 & 25,6 & 1.675 & 20,8 & 1.567 & 48,5 & 1.450 & 44,0 & 524 & 25,9 & 6.018 & 30,5 \\
Associação & 2.044 & 65,4 & 5.969 & 74,2 & 1.309 & 40,6 & 1.194 & 36,3 & 1.307 & 64,7 & 11.823 & 60,0 \\
Cooperativa & 273 & 8,7 & 368 & 4,6 & 318 & 9,9 & 606 & 18,4 & 175 & 8,7 & 1.740 & 8,8 \\
Sociedade mercantil & 8 & 0,3 & 28 & 0,3 & 34 & 1,1 & 42 & 1,3 & 15 & 0,7 & 127 & 0,6 \\
\hline Total & 3.127 & 100 & 8.040 & 100 & 3.228 & 100 & 3.292 & 100 & 2.021 & 100 & 19.708 & 100 \\
\hline
\end{tabular}

Fonte: elaborada pelo autor com base em dados do SIES (2013). Nota: Região Centro-Oeste 
O território do estado de Pernambuco conta com 1.526 empreendimentos solidários, desses, nove estão localizados na cidade de Petrolina, com 286.527 habitantes, seu Índice de Desenvolvimento Humano é de 0,747 (BRASIL, 2010).

\section{A Associação de Mulheres Rendeiras}

Fundada em 1998, a Associação de Mulheres Rendeiras tem sede no bairro José e Maria, na cidade de Petrolina, e nasceu da ideia de um grupo de mulheres que decidiu se organizar para fundar uma associação com o objetivo de promover a discussão acerca dos direitos e deveres, das questões de cidadania e de empoderamento das mulheres, bem como atuar como instrumento de geração de emprego e renda para suas associadas, com a confecção de trabalhos artesanais.

Diante do exposto, o empreendimento solidário destina-se a atender mulheres em situação de vulnerabilidade social, chefes de família, desempregadas e crianças, além de ofertar à comunidade cursos de atividades artesanais, como bordados e rendas, além de cursos de culinária.

A associação está localizada em um bairro periférico, com 13.944 habitantes (BRASIL, 2010), e é composta, em maioria, por mulheres. A comunidade na qual está inserida é de população de baixa renda, formada por comerciantes formais e informais, dispõe de um serviço de transporte urbano que não atende à demanda da população, o saneamento básico é precário, a maioria das ruas é calçada, embora algumas ainda estejam no cascalho. Dispõe de um posto de saúde da família que atende à comunidade local e aos bairros circunvizinhos, quatro escolas públicas e seis particulares, uma creche municipal, várias igrejas católicas e protestantes e a associação de moradores. É nesse cenário, e em mais onze bairros em seu entorno, que a Associação das Mulheres Rendeiras atua há mais de dez anos.

Assim, somente depois de muitos anos de luta para divulgar seus trabalhos e levar adiante seus propósitos é que a associação conseguiu estabelecer algumas parcerias com instituições oficiais, tais como Univasf, ${ }^{2}$ Codevasf $^{3}$ e Sebrae ${ }^{4}$. Tais instituições dão um suporte relevante, desde a divulgação de produtos até as despesas de custeio de viagens para expor o trabalho de suas associadas em cidades circunvizinhas e até em outras regiões, como Bahia, Distrito Federal e São Paulo.

Entretanto, apesar de todo esse suporte propiciado pelas instituições parceiras, a Associação de Mulheres Rendeiras ainda encontra grandes dificuldades em divulgar e vender os produtos artesanais, isso ocorre devido à falta de transporte, pois sentem bastante dificuldade em transportar o material para divulgar suas peças em feiras de artesanato na própria região e em outras localidades. A falta de 
acesso às linhas de crédito tradicional ainda se constitui em outro fator que parece distante da realidade de suas associadas, visto que as instituições financeiras oficiais dificultam o acesso ao crédito, alegando falta de garantias para concessão dos recursos, falta de capacidade de pagamento, baixo nível de produtividade e irregularidade das vendas. Da mesma forma, as próprias associadas não querem correr o risco de fazer algum empréstimo e não ter como cumprir com suas obrigações futuras.

\section{Procedimentos metodológicos}

Para a elaboração do presente artigo, utilizou-se como objeto de estudo a Associação de Mulheres Rendeiras do município de Petrolina, em Pernambuco. O empreendimento conta com 27 associadas, que constituiram o universo amostral, visto que todas foram entrevistas.

Realizou-se uma coleta de dados primários por meio de pesquisa descritiva, com aplicação de questionários estruturados, contendo perguntas fechadas e abertas, no universo amostral constituído pela totalidade das associadas. Houve também a formação de grupos de discussão e entrevistas com representantes de entidades parceiras do empreendimento. Por sua vez, a coleta de dados secundários foi realizada mediante consulta de dados históricos, órgãos oficiais, endereços eletrônicos, periódicos, pesquisa bibliográfica e em blogues da própria associação para aprofundar a pesquisa.

Os dados foram coletados no período de 24 a 31 de outubro de 2014 pela equipe de estudantes de Economia Solidária do curso de Administração de Empresas da Faculdade de Ciências Aplicadas e Sociais de Petrolina.

\section{Resultados e discussão}

Por meio da pesquisa de campo realizada com as associadas do empreendimento solidário de autogestão, objeto deste estudo, foi possível traçar um perfil socioeconômico dos atores envolvidos bem como identificar o mercado consumidor e os principais produtos produzidos e comercializados pela Associação de Mulheres Rendeiras em Petrolina. Foram realizadas também entrevistas com as gestoras da associação, visando identificar as principais dificuldades enfrentadas na gestão do empreendimento, propiciando identificar soluções para tornar o empreendimento sustentável, capaz de gerar emprego e renda para suas associadas, visto que a 
maioria não depende da renda proveniente da produção e comercialização dos produtos oriundos da atividade desenvolvida pelo empreendimento.

Analisando-se o Gráfico 1, acerca da faixa etária das integrantes da associação, objeto deste estudo, pode-se verificar que a maioria das associadas (90\%) encontra-se na faixa etária entre 30 e 60 anos de idade, a menor parcela das associadas com idade até 30 anos ainda faz parte da referida associação, visto que acreditam que a atividade pode se tornar rentável, apesar da dificuldade e da concorrência com a atividade rendeira de estados vizinhos, Rio Grande do Norte e Ceará. Os $9 \%$ restantes, encontram-se inclusos na faixa acima dos 60 anos, cujo perfil é de aposentadas e que realizam as atividades na associação para aumentar a renda familiar. Esse percentual encontra-se também atrelado às questões históricas e culturais, pois elas alegam que a atividade foi passada de geração em geração e que elas representam a continuidade dessa atividade.

Gráfico 1 - Faixa etária das integrantes da Associação das Mulheres Rendeiras

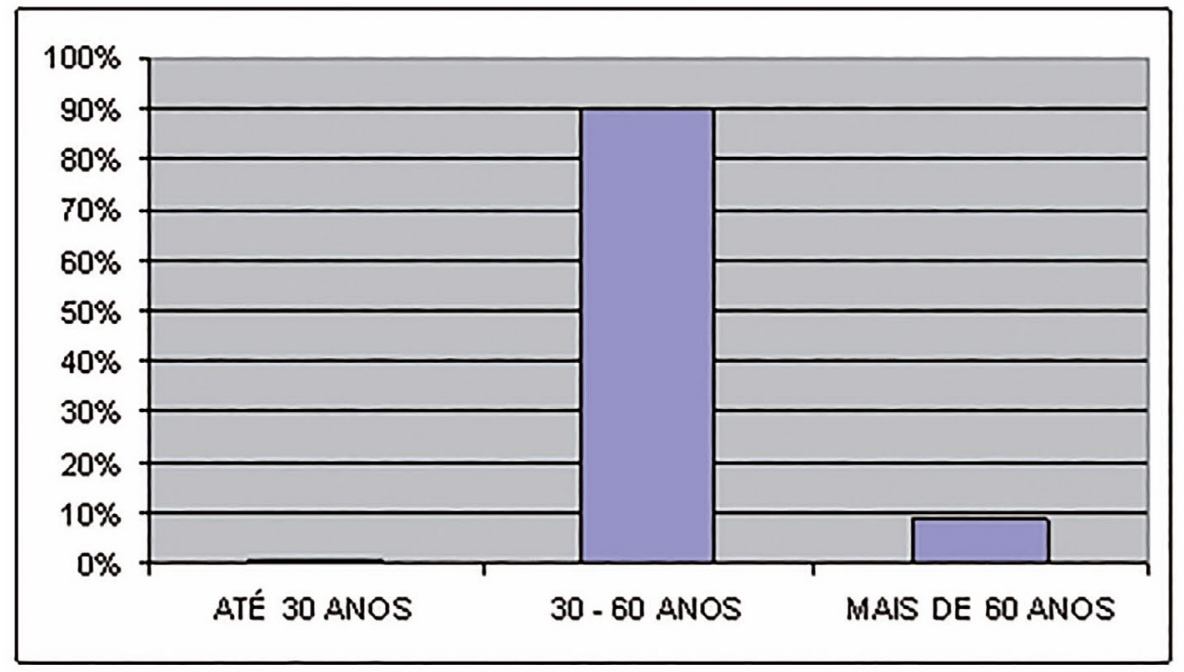

Fonte: elaborado pelo autor com base em dados da pesquisa de campo.

Conforme se verifica no Gráfico 2, quanto ao nível de escolaridade das integrantes da Associação das Mulheres Rendeiras, constatou-se um baixo nível de escolaridade e uma mão de obra não qualificada. Das integrantes da associação, 70\% estudaram até a $4^{\mathrm{a}}$ série do ensino fundamental, sendo que a maioria desse grupo está na faixa etária entre 30 e 60 anos. Entre 5\% e 25\% das associadas têm o $1^{\circ}$ ou 
o $2^{\mathrm{o}}$ grau completos e apenas uma associada tem ensino superior completo e cursa algum tipo de curso de pós-graduação. Ao ser perguntada se tinha alguma pretensão em continuar exercendo a atividade rendeira, ela afirmou, categoricamente, que não, devido a pouca rentabilidade. A Associação de Mulheres Rendeiras ainda conta com serviço de voluntários em seu processo artesanal de produção.

Gráfico 2 - Nível de escolaridade das integrantes da Associação das Mulheres Rendeiras

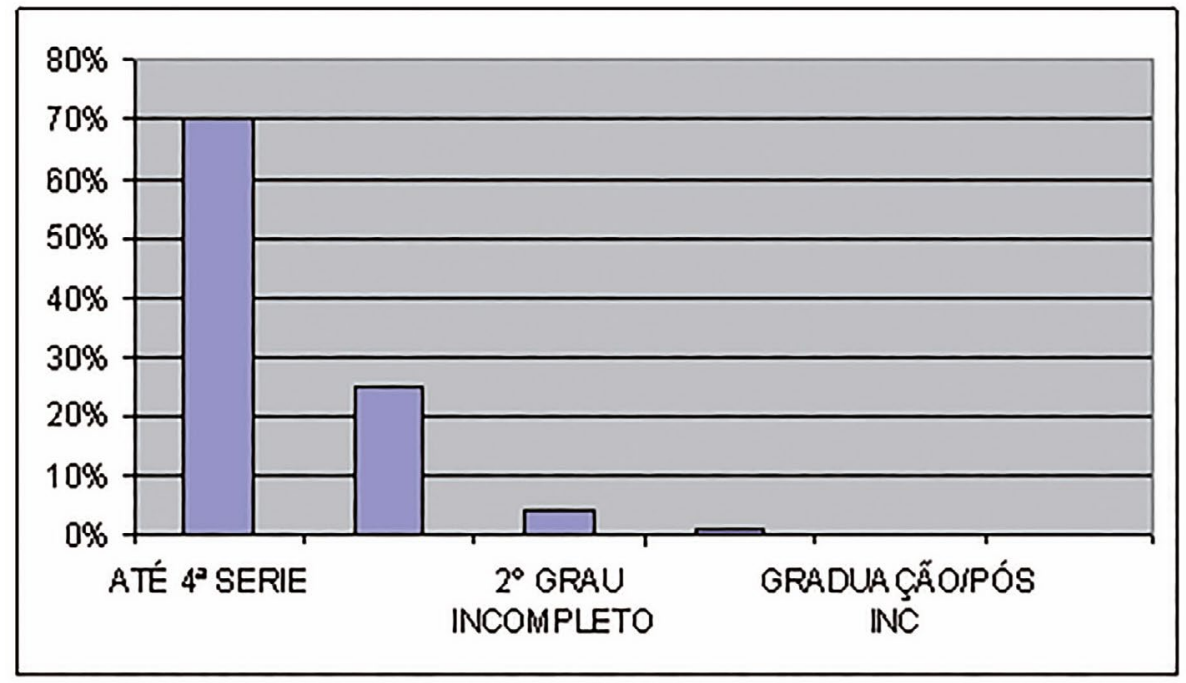

Fonte: elaborado pelo autor com base em dados da pesquisa de campo.

Entre as associadas, como demonstra o Gráfico 3, a maioria não depende da renda proveniente da atividade produtiva do empreendimento a que estão vinculadas (99\%). Apenas uma associada depende da renda mensal da associação para prover o sustento de seu filho, que necessita de cuidados especiais. Vale ressaltar que, muitas vezes, essa renda não atinge o salário mínimo vigente, sendo complementada com doações das outras associadas. 
Gráfico 3 - Grau de dependência da renda da Associação das Mulheres Rendeiras

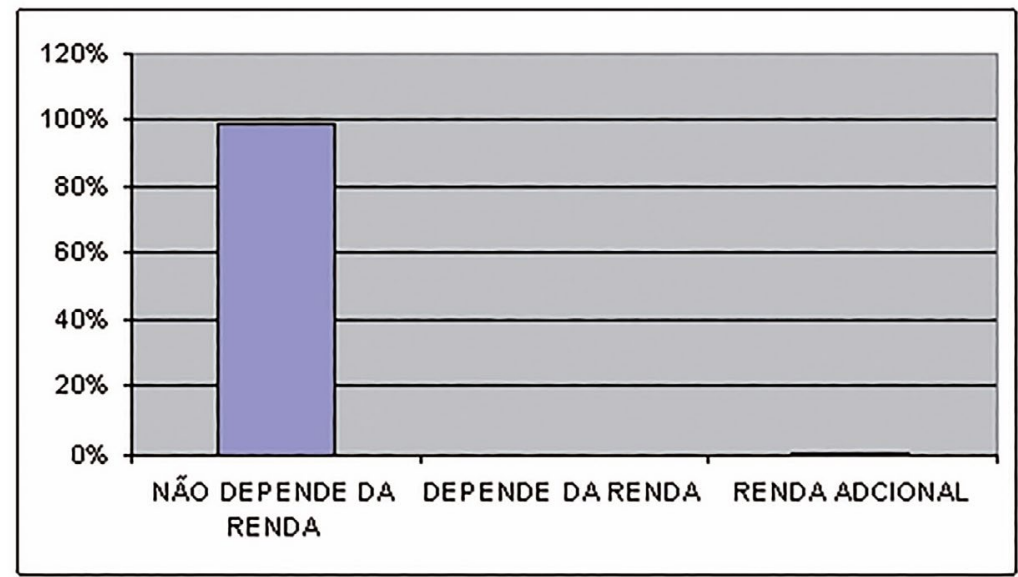

Fonte: elaborado pelo autor com base em dados da pesquisa de campo.

Embora cada associada contribua mensalmente com um valor referente a $1 \%$ do salário mínimo vigente para custear as despesas do empreendimento, nem todas frequentam diariamente a associação, ainda que compareçam de forma usual às reuniões ordinárias da associação. O quadro de associadas é muito atuante, pois todas buscam envolver-se com as atividades cotidianas da associação. Como se verifica no Gráfico 4, o número de associadas diminuiu substancialmente, visto que elas desistem ou abandonam a associação, por não verem a atividade como uma opção de trabalho com renda estável. Atualmente, o número de associadas é de 27 membros, número que permanece inalterado desde 2011.

Gráfico 4 - Numero de associadas à Associação das Mulheres Rendeiras

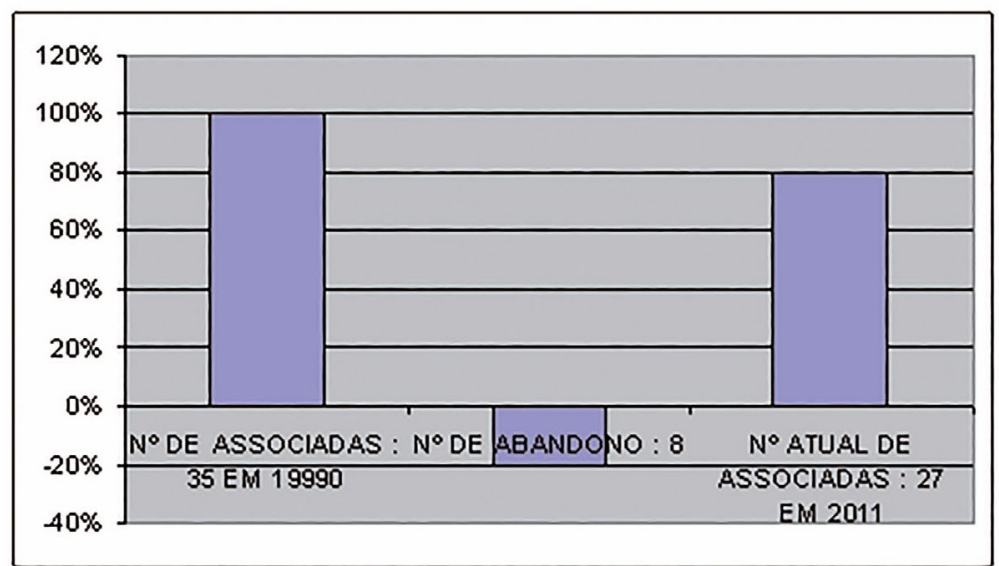

Fonte: elaborado pelo autor com base em dados da pesquisa de campo. 
O Gráfico 5 apresenta qual o mercado consumidor e o público-alvo dos produtos produzidos e comercializados pela Associação de Mulheres Rendeiras do município de Petrolina. A maioria da produção, cerca de $60 \%$, atende à demanda externa constituída por turistas em trânsito pela cidade, uma vez que são produtos artesanais e mais valorizados por pessoas de outras regiões. Do total da produção, 28\% são comercializados no âmbito doméstico, pelas donas de casa residentes no município bem como em cidades circunvizinhas. O restante da produção, $12 \%$, destina-se ao público em geral.

Gráfico 5 - Mercado consumidor dos produtos fabricados pela Associação das Mulheres Rendeiras



Fonte: elaborado pelo autor com base em dados da pesquisa de campo.

De acordo com o Gráfico 6, os produtos fabricados pela Associação de Mulheres Rendeiras são elaborados de forma artesanal, com destaque para almofadas, arranjos de flores, roupas com bordados, bolsas, toalhas, bonecas, "roupa de cozinha", objetos para decoração, tudo com detalhes em renda e em bordados. Há também produtos vindos de uma associação de produtos artesanais de Juazeiro, na Bahia. $\mathrm{Na}$ tentativa de diversificar a fonte de renda, recentemente, a associação abriu uma lanchonete para auxiliar no pagamento das despesas, embora tenham sido constatadas muitas dificuldades, já que alguns dos eletrodomésticos são alugados e outros emprestados, e as vendas não são suficientes para custear o aluguel e ainda gerar lucro para distribuir entre as associadas. Os artigos de bordados com aplicações são os produtos mais vendidos, em contrapartida, os produtos de renda, nos quais a existência da associação é baseada, são os menos vendidos por falta de mercado e por terem custo de produção mais elevado, devido ao detalhamento do trabalho. 
Gráfico 6 - Produtos fabricados pela Associação das Mulheres Rendeiras mais vendidos

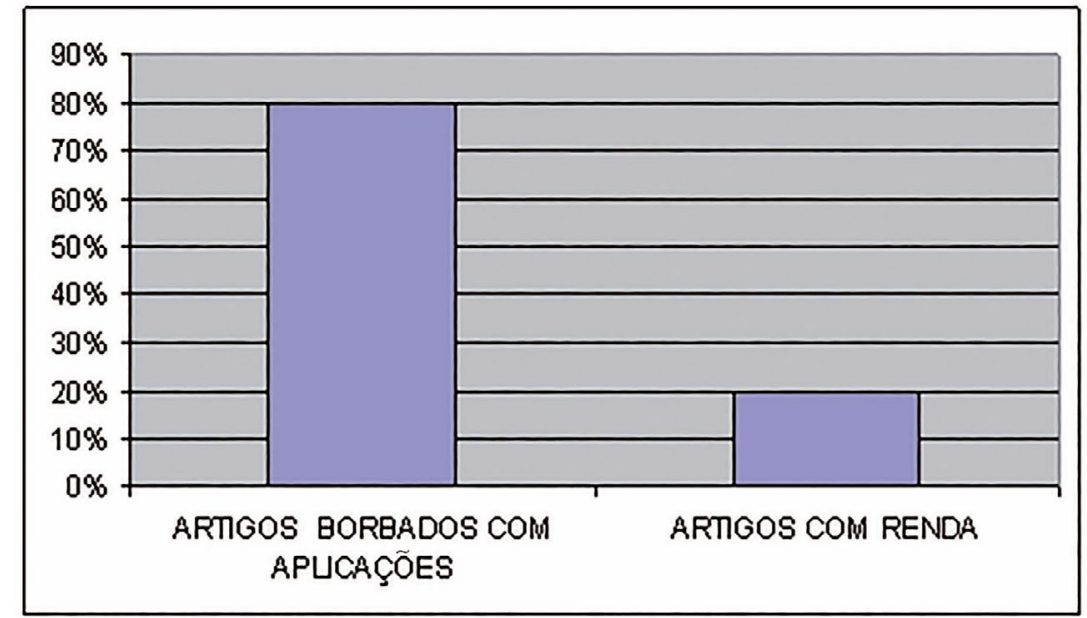

Fonte: elaborado pelo autor com base em dados da pesquisa de campo.

A renda mensal da associação varia de acordo com as vendas, o que leva as associadas a interromper a produção até que o estoque seja vendido, para então retomar a produção. A oscilação da receita proveniente das vendas, atrelada à falta de instrumentos de gestão financeira, dificulta a administração da própria associação. Não há um público específico, o consumidor pode ser o turista, a dona de casa ou estudantes. Para fazer a divulgação dos produtos em feiras e em outras cidades, a associação passa por algumas dificuldades, como o transporte dos produtos ou a necessidade de ajudantes, uma vez que a maioria das associadas são mulheres mais idosas e têm dificuldade em carregar os produtos. O Sebrae, a Codevasf e a Univasf são empresas parceiras da associação e, na maioria das vezes, patrocinadoras das viagens para a exposição dos trabalhos.

Os cursos de bordados, bonecas e flores são oferecidos pela associação ao público em geral, que demonstra interesse em aprender o fabrico de produtos artesanais. O maquinário utilizado na produção é do tipo industrial. Das cinco máquinas de costura que a associação dispõe, apenas uma encontra-se em condições de funcionamento. A dificuldade em manusear essas máquinas e o elevado custo do conserto são os motivos que levam à não utilização dos equipamentos.

Durante a pesquisa, em entrevista realizada com membros da diretoria da Associação de Mulheres Rendeiras, a maior dificuldade percebida é a falta de um meio de divulgação que valorize seus produtos e que, por ventura, otimize as vendas, o que seria o ponto principal para a obtenção de uma linha de crédito necessária para propiciar a estabilidade econômica da associação. 


\section{Considerações finais}

É recorrente na maioria dos empreendimentos econômicos solidários a falta de condições mínimas, como dispõem as empresas capitalistas: facilidade de acesso a financiamento com baixa taxa de juros, acesso à tecnologia adequada, à pesquisa, à formação e à qualificação dos trabalhadores de forma continuada e assistida, além da falta de infraestrutura, etc.

A pesquisa realizada com as associadas da Associação de Mulheres Rendeiras do município de Petrolina aponta algumas dificuldades que colocam em risco a continuidade do empreendimento econômico solidário. Uma delas consiste na dificuldade em acessar linhas de crédito tradicional. A constituição de uma cooperativa poderia facilitar o acesso ao crédito por meio da captação de recursos voltados especificamente para atender a esse tipo de empreendimento, o que iria proporcionar melhor aproveitamento econômico da produção com aquisição de máquinas de costura modernas. Entretanto, não há, dentro do atual grupo de associadas, quem tenha conhecimento de gestão para gerir esse tipo de empreendimento devido à sua complexidade. A associação permaneceria funcionando, atendo-se apenas ao cumprimento de sua função social.

Outro desafio é gerar renda suficiente para atender às necessidades de suas associadas, visto que a associação não consegue manter uma produção regular e suas vendas são esporádicas. A inserção de seus produtos poderia alcançar outros mercados com a atuação em redes de cooperação, o comércio justo e a participação continuada em eventos em outras regiões.

Em consonância com o exposto, entende-se que trabalhar a questão social de maneira concreta é algo que reproduz a importância de transformar vidas, modificar cenários outrora abatidos pela problemática social e pela falta de oportunidade de as pessoas desenvolverem seus talentos e construírem uma história de cidadania e superação. O que se pode perceber, em experiências como a da Associação das Mulheres Rendeiras, é o fortalecimento de ações que contribuíram significativamente para a construção de uma sociedade justa, sustentável e solidária, em que o empoderamento das pessoas acabe por se tornar um importante mecanismo capaz de fortalecer os indivíduos em sentido social, político e econômico, como também do ponto de vista da formação dos atores sociais envolvidos nesse processo.

Dessa forma, o mundo, cada vez mais globalizado, desenvolvido tecnologicamente e repleto de transformações de mercado, deixa, porém, uma gama de pontos de melhoria que devem ser trabalhados por organizações públicas, privadas e do terceiro setor, e isso tudo parte do talento de cada indivíduo, do controle social e, 
principalmente, da capacidade financeira do negócio. É crescente a necessidade de ações empreendedoras que se movam na direção da resolução de muitas das demandas sociais que afetam a qualidade de vida dos cidadãos.

Sendo assim, as diversas articulações que viabilizam o trabalho na Associação das Mulheres Rendeiras evidenciam o quanto é fundamental a construção de parcerias e a colaboração de diversos segmentos sociais, alinhados em torno da busca por um cenário que contemple questões como melhoria da educação, redução da ociosidade, valorização da cultura, amplo debate em torno da cidadania e, consequentemente, diminuição da marginalização social.

Destarte, este estudo evidencia uma experiência prática e motivadora que contradiz muitos dos discursos que se limitam a um plano meramente filosófico ou materialista, na medida em que dinamiza relações, transforma vidas e cenários sociais, retrata a importância de as pessoas se colocarem como protagonistas de suas histórias, enquanto empreendedoras, cidadãs e boas administradoras de seus projetos de vida, com sensibilidade para agir de maneira positiva, tanto no aspecto individual quanto coletivo. 


\title{
Solidarity economy an alternative to job creation and income in territory semiarid: difficulties and prospects
}

\begin{abstract}
This job aims to show the socioeconomic profile and the associated bottlenecks that hinder the survival of joint ventures economy, in particular the Women's Association Tenants in the city of Petrolina-PE, preventing them often coming act as an instrument for generating employment and income in an area with few economic opportunities. The methodology used for the elaboration of this work consisted of desk research and a secondary data collection performed by applying structured questionnaires in a sample universe of 27 (twenty seven) members, held from 24 to 31 October 2013. was concluded that the difficulty of access to traditional conventional credit lines, lack of knowledge of management tools and lack of activity in the solidarity networks constitute the main obstacles to the sustainability of this type of solidarity and self-managed enterprise.

Keywords: Associations. Generation of employment and income. Solidarity economy.

\section{Economía solidaria una alternativa para la generación de empleo e ingresos en territorio semiárido: dificultades y perspectivas}

\section{Resumen}

Este trabajo tiene como objetivo mostrar el perfil socioeconómico de los cuellos de botella asociados y que dificultan la supervivencia de las empresas de economía social, en particular, la Asociación de Mujeres Rendeiras en la ciudad de Petrolina, evitando que a menudo vienen a actuar como la generación de empleo y de ingresos instrumento en una zona con pocas oportunidades económicas. La metodología utilizada para la preparación de este trabajo consistió en la investigación documental y una colección de datos secundario realizado mediante la aplicación de cuestionarios estructurados en un universo muestra de 27 (veintisiete) miembros, celebrada del 24 al 31 de octubre de 2014, se concluyó que la dificultad de acceso a las líneas tradicionales de crédito convencionales, la falta de conocimiento de los instrumentos de gestión y la falta de acción en las redes de solidaridad constituyen los principales obstáculos para la sostenibilidad de este tipo de solidaridad y de la empresa autogestionada.

Palabras clave: Asociaciones. Economía solidaria. El empleo y la generación de ingresos. 


\section{Notas}

2 Universidade Federal do Vale do São Francisco.

3 Companhia de Desenvolvimento dos Vales do São Francisco e Parnaíba.

4 Serviço de Apoio à Pequena e Média Empresa.

\section{Referências}

ARCOVERDE, Ana Cristina Brito. Economia solidária em Pernambuco: alternativa de emancipação frente ao desemprego e à exclusão social? Recife: UFPE, 2009.

BRASIL. Ministério do Planejamento, Orçamento e Gestão. Instituto Brasileiro de Geografia e Estatística. Contagem Populacional 2010. Brasília, DF, 2010. Disponível em: <http://www.sidra. ibge.gov.br/bda/popul/default.asp?t=3\&z=t\&o=22\&u1=1\&u2=1\&u4=1\&u5=1\&u6=1\&u3=34>. Acesso em: 10 jan. 2014.

LIMA, Maria Isabel Rodrigues. Economia solidária e vínculos. São Paulo: Ideias \& Letras, 2013.

PINTO, G. A. A organização do trabalho no século $X X$ : taylorismo, fordismo e toyotismo. São Paulo: Expressão Popular, 2007.

SINGER, Paul. O Brasil na crise: perigos e oportunidades. São Paulo: Contexto, 1999.

SINGER, Paul; SOUZA, André Ricardo de. A economia solidária no Brasil: a autogestão como resposta ao desemprego. São Paulo: Contexto, 2000.

SISTEMA NACIONAL DE INFORMAÇÕES EM ECONOMIA SOLIDÁRIA. Projeto Sies - Grupo de Pesquisa em Economia Solidária e Cooperativa da Unisinos. 2013. Disponível em: <http:// sies.ecosol.org.br>. Acesso em: 16 fev. 2017. 